\title{
The predictive and prognostic value of sex in localized colorectal cancer: a SEER-based analysis
}

\author{
Bin Ma^, Yongmin Li, Qingkai Meng \\ Department of Colorectal Surgery, Cancer Hospital of China Medical University, Liaoning Cancer Hospital and Institute, Shenyang, China \\ Contributions: (I) Conception and design: B Ma; (II) Administrative support: B Ma, Q Meng; (III) Provision of study materials: B Ma; (IV) Collection \\ and assembly of data: B Ma, Y Li; (V) Data analysis and interpretation: B Ma, Q Meng; (VI) Manuscript writing: All authors; (VII) Final approval of \\ manuscript: All authors. \\ Correspondence to: Bin Ma. Department of Colorectal Surgery, Cancer Hospital of China Medical University, Liaoning Cancer Hospital and Institute, \\ No. 44 Xiaoheyan Road, Dadong District, Shenyang 110042, China. Email: mabin0326cmu@163.com.
}

Background: Although the influence of sex on different cancer survival has been investigated, the predictive and prognostic value of sex in localized colorectal cancer (CRC) still remain controversial.

Methods: Survival was evaluated in patients who diagnosed with localized CRC in the Surveillance, Epidemiology, and End Results (SEER) database between 2004 and 2016. Overall survival (OS) outcomes were estimated with the Kaplan-Meier method, and multivariable Cox regression was used to calculate hazard ratios (HRs) and 95\% confidence intervals (CIs).

Results: We obtained a dataset that included 70,836 males and 69,705 females of localized CRC patients. Compared with males, females more often had age $\geq 75$ years $(55.1 \%$ vs. $44 \%$ ), right-sided colon cancer ( $56.8 \%$ vs. $45.4 \%$ ), and more advanced $\mathrm{pT}$ stage cancer $(75.5 \%$ vs. $72 \%$ ). In addition, we found that females had better OS than males and that sex could be an independent factor of OS in T1-3N0M0 (Stage I-II) colon cancer (regardless of right/left-sided tumour) and T1-2N0M0 (Stage I) rectal cancer (each HR <1, each $\mathrm{P}<0.05)$. Although a significant OS benefit was not observed in T3N0M0 rectal cancer in the overall analysis $(\mathrm{P}=0.183)$, females who underwent postoperative chemotherapy had better OS than males among T3N0M0 (Stage II) rectal cancer patients significantly $(\mathrm{P}<0.001)$.

Conclusions: In our study, sex was shown to be a prognostic factor in localized-CRC. In particular, females may benefit more from postoperative chemotherapy than males with T3N0M0 (Stage II) rectal cancer.

Keywords: Sex; colorectal cancer (CRC); Surveillance, Epidemiology, and End Results dataset (SEER dataset); prognosis; predictor

Submitted Dec 11, 2020. Accepted for publication Apr 02, 2021.

doi: $10.21037 /$ tcr-20-3421

View this article at: http://dx.doi.org/10.21037/tcr-20-3421

\section{Introduction}

Cancer is the main global public health problem and is also the second primary cause of death in the USA (1). Colorectal cancer (CRC) is one of the most common malignant tumours in the United States. In terms of incidence, CRC is the third most common cancer, with an estimated 78,300 new cases (9\% of all new cancers) and 69,650 new cases ( $8 \%$ of all new cancers) in the male and female population in 2020 (1). In terms of mortality, CRC is the third most common cause of cancer death, with a total of 28,630 deaths ( $9 \%$ of all cancers) and 24,570 deaths (9\% of all cancers) expected in males and females in 2020 (1).

\footnotetext{
$\wedge$ ORCID: 0000-0002-0727-4536.
} 
Although the morbidity and mortality of CRC rank third in both males and females in the estimated data, there are some differences between the sexes. In the vast majority of cancers, there are some differences between males and females in morbidity and prognosis, which may be the reason why cancer data of males and females are separated.

The influence of sex on CRC has also been a hot topic in recent years. Several studies have shown that sex is an independent prognostic factor for CRC and that females generally have longer survival times than males (2-8). Compared to males of all ages, females are less likely to be diagnosed with CRC $(9,10)$. In addition, one study looked at cumulative 10 -year incidence and mortality of CRC reached among men at ages 50, 55, and 60, and found that women mainly reached equivalent levels when 4 to 8 years older (11). There are several probable explanations that sex differences in CRC extend to environmental influence, tumour biology, and therapeutic response (12). Postmenopausal hormone use has been linked to a $40 \%$ reduction in CRC in the Women's Health Initiative trial (13). Use of hormone replacement therapy was associated with a statistically significant improved survival and reduced risk from colon cancer $(14,15)$. The clinicopathologic features of tumours may be different between males and females. There is also evidence that women are more likely to develop right-sided colon cancer with microsatellite instability $(16,17)$. Furthermore, some reports suggest that females present at a more advanced stage of cancer (18) on average. All aforementioned differences should be taken into account as confounding factors.

We selected patients aged 60 years and over (menopause) and patients with stage T1-4N0M0 for analysis after stratification of the primary tumour site. Our aim was to assess the prognostic effect of sex on survival after reduce of known confounding factors. We present the following article in accordance with the STROBE reporting checklist (available at http://dx.doi.org/10.21037/tcr-20-3421).

\section{Methods}

\section{Patients}

The study was conducted in accordance with the Declaration of Helsinki (as revised in 2013). Between 2004 and 2016, patients diagnosed with malignant primary CRC were included in the study. The disease was defined by International Classification of Diseases for Oncology, third edition (ICD-O-3) codes (18.0, 18.2-18.7, 19.9 and 20.9). All patients who were diagnosed with CRC at or above the age of 60 underwent primary tumour resection. The patients were excluded from this study population if they (I) died within 30 days after tumour resection; (II) had Tis, N1, N2 or M1 cancer; (III) history or previous cancer; or (IV) lacked records of pathological stage, followup or histological subtype. These cases were organized by Surveillance, Epidemiology, and End Results (SEER)'s coding schemes. On the basis of the primary location of the tumour, patients were divided into three groups. This study contains only T1-T4N0M0 CRC, so we define it as localized-stage CRC. Right-sided colon cancers were defined as those arising from the caecum (C18.0), ascending colon (C18.2), hepatic flexure of the colon (C18.3) or transverse colon (C18.4); left-sided colon cancer was defined as those arising from the splenic flexure of colon (C18.5), descending colon (C18.6), and sigmoid colon (C18.7); rectum cancers were defined as those developing from the rectosigmoid junction (C19.9) or rectum (C20.9).

\section{Data collection}

This study population was assembled from the National Cancer Institute's SEER Program. SEER data include cancer cases from different locations and sources across the United States. Only a limited number of registration agencies have been collected since 1973. The dataset continues to broaden by including more geographic areas and demographic groups. It covers approximately $28 \%$ of the US. population and includes data from various geographic areas, including incidence, prevalence, mortality, population-based variable quantities, main characteristics of the tumour, and other attributes. SEER*Stat software version 8.3.6 was used to gather the main data.

\section{Statistical analysis}

The chi-square test was used to compare the baseline characteristics of males and females. Overall survival outcomes were estimated with the Kaplan-Meier (KM) method, and the differences between survival were compared by the log-rank test. A total of ten variables including sex, age, race, histological grade, chemotherapy, marital status, histology, radiotherapy, pT category and primary site, which were used in Univariate COX regression analysis. Multivariable Cox regression was used to calculate hazard ratios (HRs) and 95\% confidence intervals (CIs). 
All analyses were double-sided, and a $\mathrm{P}$ value lower than 0.05 was deemed statistically significant. All analyses were performed using the statistical software STATA ${ }^{\circledR} 8.0$ (STATA Inc., College Station, TX, USA).

\section{Results}

\section{Demographic characteristics of male and female CRC in localized-stage CRC}

We obtained a dataset that included 70,836 cases of CRC in males and 69,705 cases of T1-4N0M0CRC in females. The characteristics of CRC and the chi-square test for comparison of male and female CRC are shown in Table 1. We found significant differences in age, race, histological grade, chemotherapy, marital status, histology, radiation, pT category and primary site (each $\mathrm{P}<0.001)$. Compared with males, females more often had age $\geq 75$ years $(55.1 \%$ vs. $44 \%$ ), right-sided colon cancer ( $56.8 \%$ vs. $45.4 \%)$, and more advanced $\mathrm{pT}$ stage cancer $(75.5 \%$ vs. $72 \%)$.

\section{Influence of sex on OS after stratification by pT stage in T1-3NOMOCRC}

There was a significant difference in survival between males [Median Survival Time (MST): $124 \mathrm{~m}$ ] with CRC and females (MST: 130m) with CRC in the T1 category $(\mathrm{P}<0.001$, Figure $1 A)$. There were similar significant differences in the T2 (MST: $107 \mathrm{~m}$ in Males vs. $113 \mathrm{~m}$ in Females) and T3 (MST: $89 \mathrm{~m}$ in Males vs. $98 \mathrm{~m}$ in Females) categories $(\mathrm{P}<0.001$, Figure $1 B$; $\mathrm{P}<0.001$, Figure $1 C)$. In the $\mathrm{T} 4$ category, we discovered no difference in survival between male (MST: $54 \mathrm{~m}$ ) CRC and female (MST: $54 \mathrm{~m})$ CRC ( $\mathrm{P}=0.784$, Figure 1D). In consideration of the above outcomes, we held T4 CRC out of our analyses. The multivariable Cox regression (Table 2) showed that sex was an independent prognostic factor in overall T1-3N0M0 CRC (HR $=0.716$; 95\% CI, $0.703-0.730 ; \mathrm{P}<0.001)$. At the same time, the remaining variables are independent prognostic factors, including age, race, histological grade, chemotherapy, marital status, histology, radiotherapy, $\mathrm{pT}$ category and primary site.

\section{Influence of sex on OS after stratification by primary site in T1-3NOMOCRC}

\section{T1N0M0 category}

In right-sided colon cancer, there was no significant differences in survival between male and female $(\mathrm{P}<0.066$, Figure $2 A)$. In left-sided colon and rectal cancer, there were significant differences in survival between male and female $(\mathrm{P}<0.001$, Figure 2B; $\mathrm{P}<0.001$, Figure $2 C)$.

\section{T2N0M0 category}

Within right-sided colon, left-sided colon or rectum cancers, we discovered significant differences in survival between male and female patients $(\mathrm{P}<0.001$, Figure $2 D, E, F)$.

\section{T3N0M0 category}

We discovered significant differences in survival between male patients and female patients with right-sided colon and left-sided colon cancer $(\mathrm{P}<0.001$, Figure $2 G, H)$. In the rectum, there was no significant differences in survival between male and female $(\mathrm{P}=0.183$, Figure $2 I)$.

\section{Multivariable Cox regression}

In T1N0M0 category, we discovered significant differences of in multivariable Cox regression (Table S1), and sex and remaining variables in table were shown to be independent prognostic factors in right-sided colon cancer $(\mathrm{HR}=0.74$, 95\% CI, 0.70-0.79, $\mathrm{P}<0.001$, Figure 3), left-sided colon cancer $(\mathrm{HR}=0.73,95 \% \mathrm{CI}, 0.71-0.76, \mathrm{P}<0.001$, Figure 3$)$ and rectal cancer $(\mathrm{HR}=0.69,95 \% \mathrm{CI}, 0.64-0.74, \mathrm{P}<0.001$, Figure 3); In T2N0M0 category, we also discovered the same significant difference in multivariable Cox regression (Table S2), where sex and remaining variables in table were shown to be independent prognostic factors in right-sided colon, left-sided colon and rectal cancer ( $\mathrm{HR}=0.71,95 \%$ CI, 0.68-0.75, $\mathrm{P}<0.001$; HR $=0.68,95 \%$ CI, 0.62-0.74, $\mathrm{P}<0.001 ; \mathrm{HR}=0.71,95 \%$ CI, 0.66-0.77, $\mathrm{P}<0.001$, Figure 3); In T3N0M0 category, we also discovered that sex and remaining variables in table were independent prognostic factors in right-sided and left-sided colon cancer $(\mathrm{HR}=0.72$, 95\% CI, 0.70-0.75, P<0.001; HR =0.71, 95\% CI, 0.67-0.75, $\mathrm{P}<0.001$, Figure 3, Table S3). But we found that sex is not an independent prognostic factor in T3N0M0 rectal cancer. In T4N0M0 category, we didn't discover the significant difference in multivariable Cox regression in right-sided colon, left-sided colon and rectal cancer ( $\mathrm{HR}=0.97,95 \%$ CI, 0.93-1.02; HR =0.96, 95\% CI, 0.92-1.01; HR =0.99, 95\% CI, 0.94-1.05, Figure 3).

\section{Influence of sex and postoperative chemotherapy on OS in rectum of T3NOMO}

In order to explore the reason why sex could not distinguish 
Table 1 Characteristics of males and females CRC

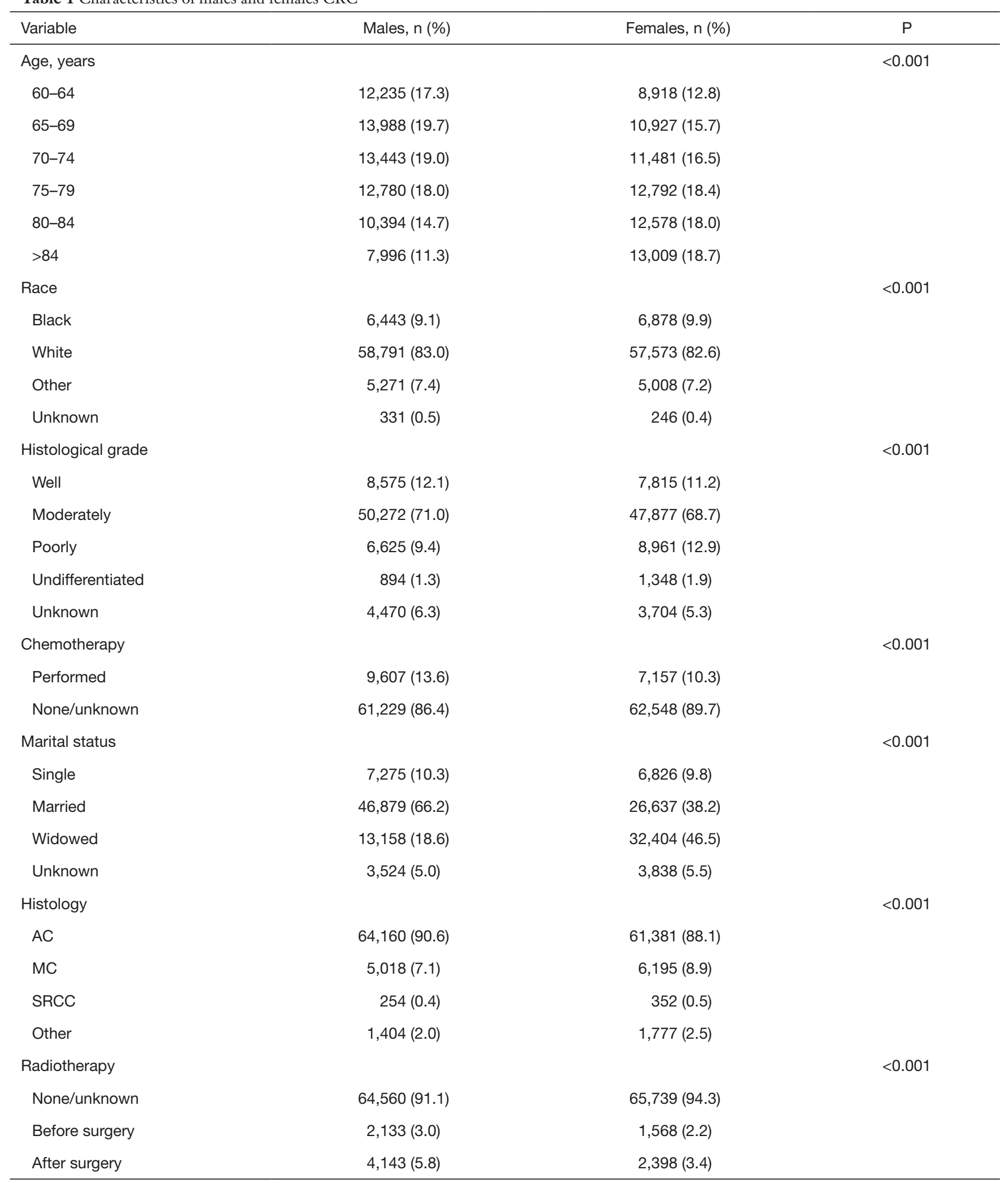

Table 1 (continued) 
Table 1 (continued)

\begin{tabular}{lcc}
\hline Variable & Males, $\mathrm{n}(\%)$ & Females, $\mathrm{n}(\%)$ \\
\hline pT category & & \\
T1 & $19,866(28.0)$ & $17,060(24.5)$ \\
T2 & $14,954(21.1)$ & $15,142(21.7)$ \\
T3 & $31,654(44.7)$ & $32,009(45.9)$ \\
T4 & $4,362(6.2)$ & $5,494(7.9)$ \\
Primary site & & \\
Right-sided colon & $32,175(45.4)$ & $39,569(56.8)$ \\
Left-sided colon & $20,701(29.2)$ & $17,051(24.5)$ \\
Rectum & $17,960(25.4)$ & $13,085(18.8)$ \\
\hline
\end{tabular}

AC, adenocarcinoma; MC, mucinous adenocarcinoma; SRCC, signet ring cell carcinoma.

the prognosis among $\mathrm{T} 3 \mathrm{~N} 0 \mathrm{M} 0$ rectum patients, we further conducted subgroup analyses. Taking all tumours of the T3N0M0 rectum category (Figure 4), patients with postoperative chemotherapy had a better survival benefit than individuals without postoperative chemotherapy among females $(\mathrm{P}<0.001)$ or males $(\mathrm{P}<0.001)$. In addition, there was no significant difference in survival between males and females without postoperative chemotherapy $(\mathrm{P}=0.634)$. However, we found that females had a better survival benefit than males in the $\mathrm{T} 3 \mathrm{~N} 0 \mathrm{M} 0$ rectumcategory with postoperative chemotherapy $(\mathrm{P}<0.001)$.

\section{Influence of sex on OS stratified by age/race/histology in T1-3NOMOCRC}

In six different age groups (Table S4), we found that females had a better survival benefit than males regardless of age and $\mathrm{T}$ category (each $\mathrm{HR}<1$, each $\mathrm{P}<0.001$ ). Meanwhile, in patients of the white race (Table S4), we found that females had a better survival benefit than males in the T1, $\mathrm{T} 2$ and $\mathrm{T} 3$ categories $(\mathrm{HR}=0.933,95 \% \mathrm{CI}, 0.897-0.970$, $\mathrm{P}<0.001 ; \mathrm{HR}=0.910,95 \%$ CI, 0.875-0.947, $\mathrm{P}<0.001$; $\mathrm{HR}=0.935$, 95\% CI, 0.911-0.959, $\mathrm{P}<0.001)$. Moreover, in different groups of histological types (Table S4), we found that females had a survival benefit over males among adenocarcinoma histological type patients in the T1, T2 and T3 categories (respectively, HR $=0.926,95 \%$ CI, 0.893$0.960, \mathrm{P}<0.001 ; \mathrm{HR}=0.895,95 \%$ CI, 0.861-0.930, $\mathrm{P}<0.001$;
$\mathrm{HR}=0.902,95 \%$ CI, $0.880-0.926, \mathrm{P}<0.001)$.

\section{Discussion}

CRC is one of the most common cancers all over the world (1). There are many differences between males and females in morbidity, mortality, prognosis, and biological behaviour for most cancers (19-24). The sex differences in cancer survival have attracted great attention because they may be a signal of basic biological differences between males and females in cancer pathogenesis and treatment response, which can be incorporated into management strategies $(25,26)$. Therefore, sex differences are an essential research direction in tumour research. Interestingly, females seem to have better outcomes in most tumours, such as low morbidity, low mortality, and better prognosis. Moreover, a systematic review indicated that female patients also often have a survival advantage over male patients in many cancers (27). Among the sex differences in some cancer manifestations, researchers have found that some may be related to male occupational and environmental exposures (28). Nevertheless, in many circumstances, despite the control of environmental and genetic factors, the sex differences found in many cancers remain unexplained $(29,30)$. Our study focused on the prognostic impact of sex on localized CRC. CRC is one of the most common malignant tumors in the U.S. It is the third most common tumour in both male and female 
A

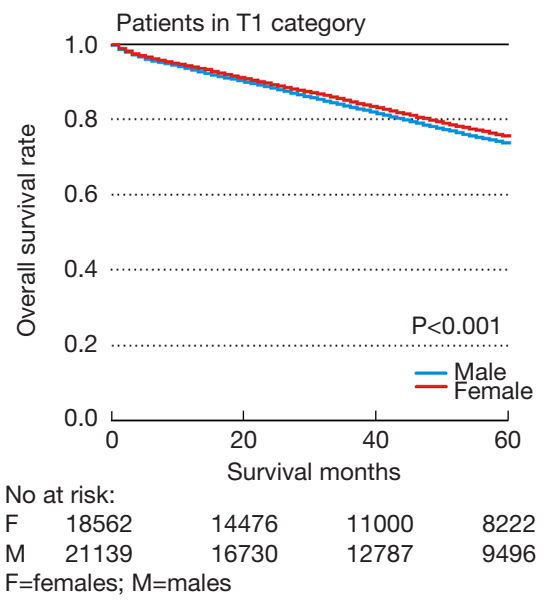

C

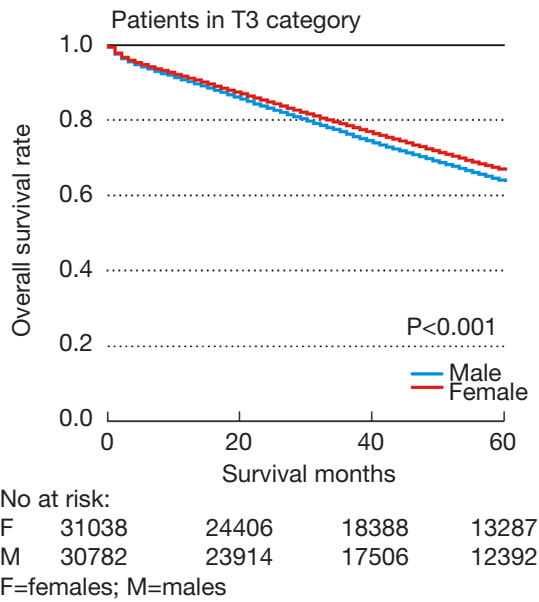

B

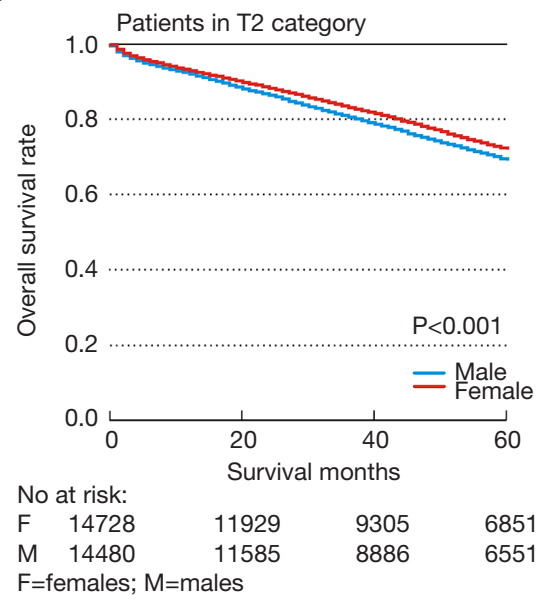

D

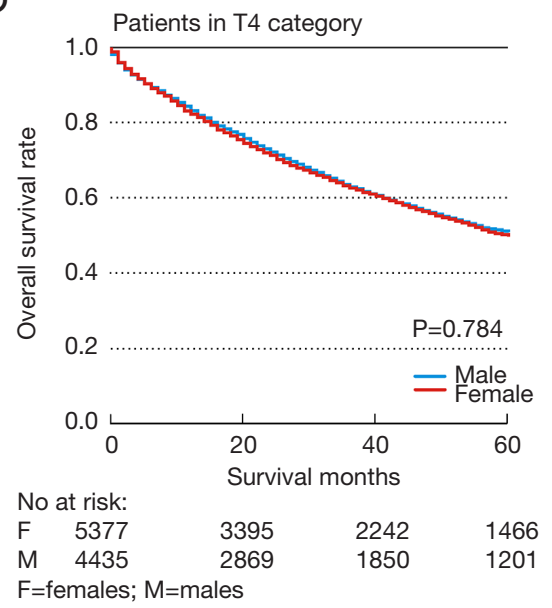

Figure 1 Kaplan-Meier comparison of overall survival among localized-stage CRC patients with males and females stratified by $\mathrm{T}$ category. (A) Patients in T1 category; (B) patients in T2 category; (C) patients in T3 category; (D) patients in T4 category.

Table 2 Prognostic factors in COX proportional hazard model

\begin{tabular}{|c|c|c|c|c|c|c|}
\hline \multirow{2}{*}{ Variable } & \multicolumn{2}{|c|}{ Univariate analysis } & \multirow{2}{*}{$\mathrm{P}$} & \multicolumn{2}{|c|}{ Multivariate analysis } & \multirow{2}{*}{$\mathrm{P}$} \\
\hline & $\mathrm{HR}$ & $95 \% \mathrm{Cl}$ & & $\mathrm{HR}$ & $95 \% \mathrm{Cl}$ & \\
\hline Sex* & & & $<0.001$ & & & $<0.001$ \\
\hline Female & 0.93 & $0.91-0.94$ & & 0.72 & $0.70-0.73$ & \\
\hline Age, years* & & & $<0.001$ & & & $<0.001$ \\
\hline $65-69$ & 1.35 & $1.30-1.41$ & & 1.37 & $1.31-1.43$ & \\
\hline $70-74$ & 1.88 & $1.81-1.96$ & & 1.91 & $1.84-1.99$ & \\
\hline $75-79$ & 2.73 & $2.63-2.84$ & & 2.79 & $2.68-2.89$ & \\
\hline $80-84$ & 3.94 & $3.79-4.09$ & & 3.98 & $3.83-4.13$ & \\
\hline
\end{tabular}

Table 2 (continued) 
Table 2 (continued)

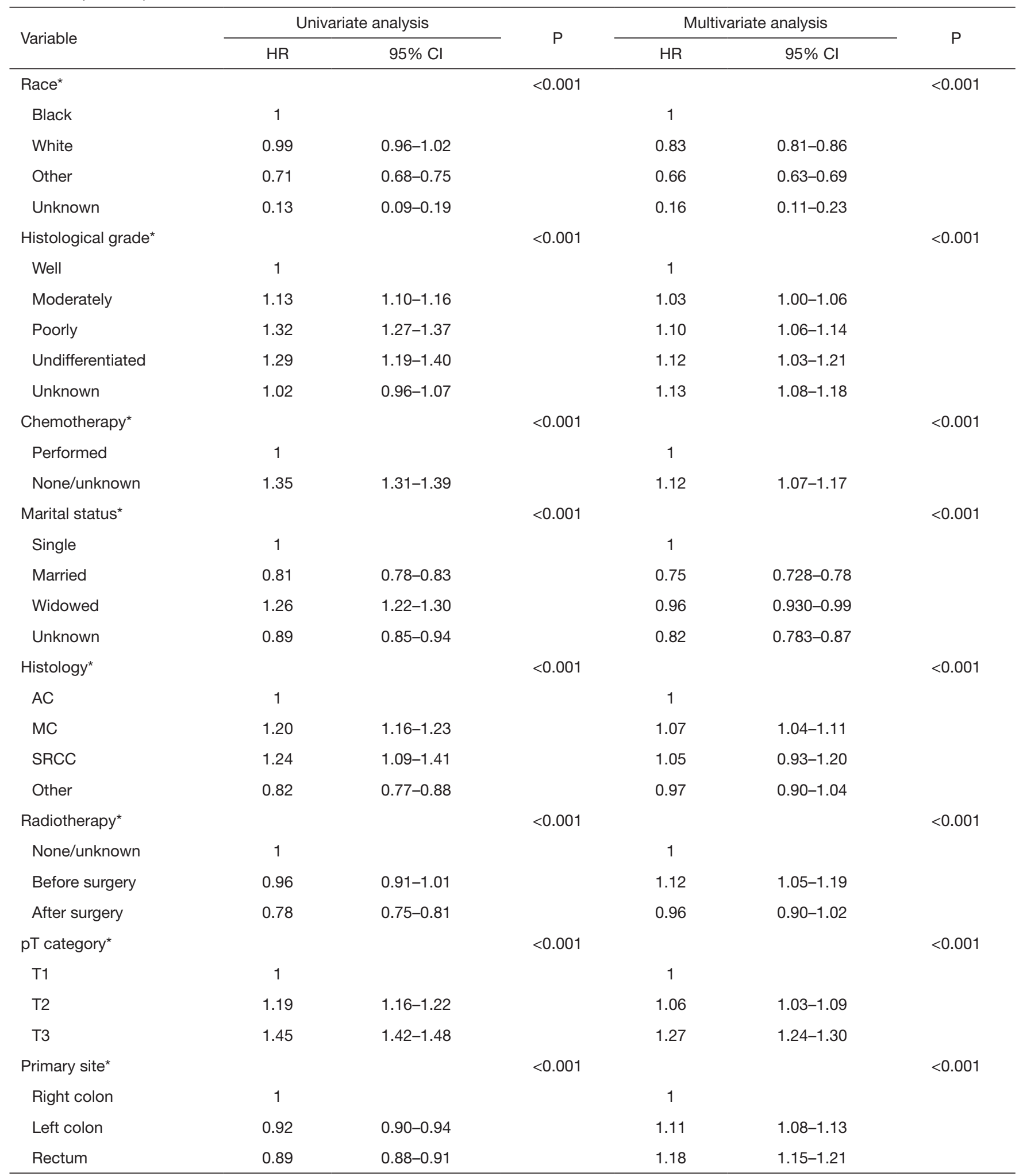

All variables were used in univariate analysis. *Variables significantly associated with survival were included in the multivariate analysis. AC, adenocarcinoma; MC, mucinous adenocarcinoma; SRCC, signet ring cell carcinoma; HR, hazard ratio; Cl, confidence interval. 
A

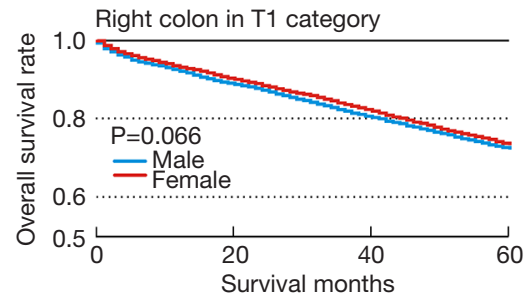

D

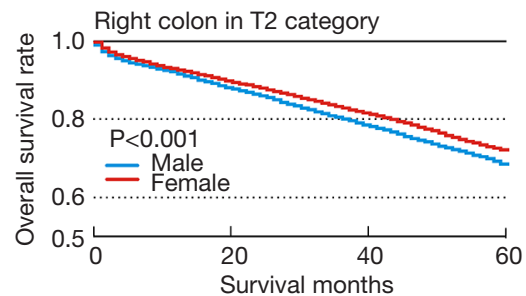

G

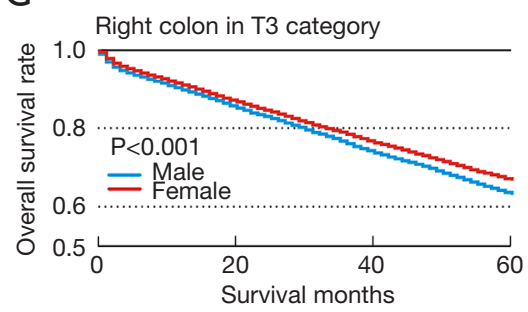

B

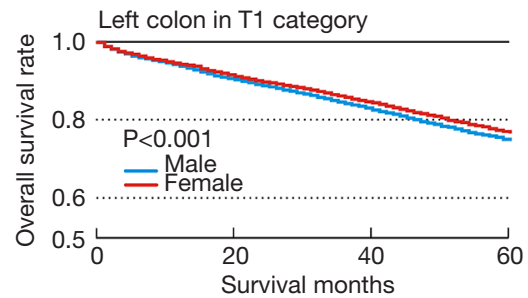

E

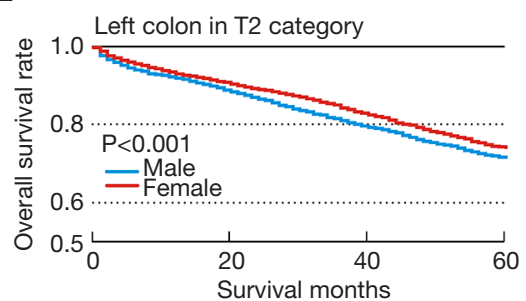

$\mathrm{H}$

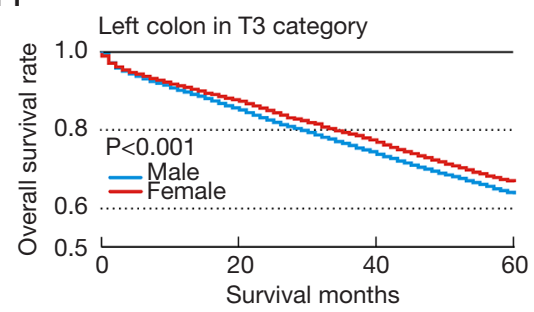

C

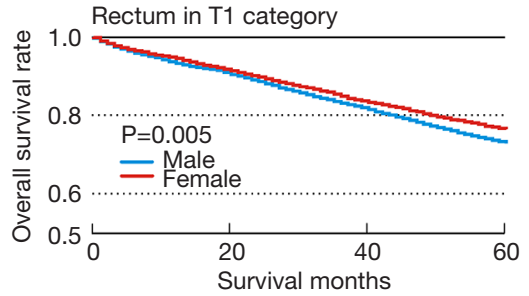

F

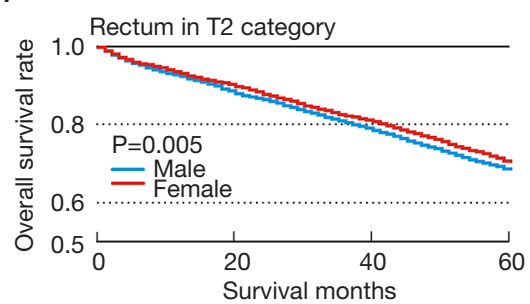

I

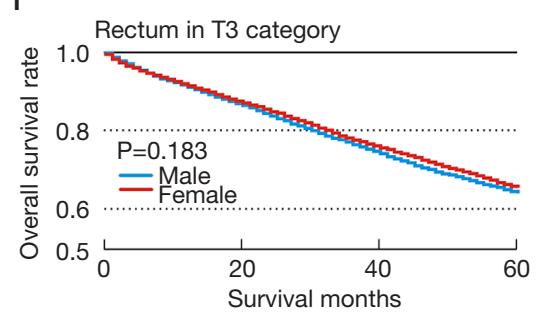

Figure 2 Kaplan-Meier comparison of overall survival among T1-3N0M0 CRC patients with males and females stratified by T category and primary site. (A) Right colon in T1 category; (B) left colon in T1 category; (C) rectum in T1 category; (D) right colon in T2 category; (E) left colon in T2 category; $(\mathrm{F})$ rectum in T2 category; $(\mathrm{G})$ right colon in T3 category; (H) left colon in T3 category; (I) rectum in T3 category.

patients. The estimated new cases in 2020 will be 78,300 in males and 69,650 in females. Among all tumors, the mortality rate of CRC ranks third among males and females. The data for 2020 projected deaths are 28,630 male patients and 24,570 female patients. Although the morbidity and mortality of CRC rank third in both male and female patients, there are some differences in their morbidity, mortality and prognosis. The influence of sex on CRC has also been a hot topic in recent years. In 2001, a German study surveyed nearly 900 patients and concluded that being female was related to improved long-term survival in rectal cancer (6). In 2003, a similar study evaluated 3,200 cases and found that females had a survival benefit in CRC (5). More studies have indicated that sex is an independent prognostic factor in CRC, and females usually live longer than males (2-8). Other studies indicated that females improved OS compared with males $(3,5,31,32)$. Compared to males of all ages, females are less likely to have CRC $(9,10)$. In fact, their risk is equivalent to that of males 4 to 8 years younger (11). Meanwhile, OS of female is better in primary disease, even if the age of female at the diagnosis was higher than male. Thus, the effect of sex on CRC is well recognized. Although a large number of studies have shown that the female prognosis is better than male prognosis in many cases, there were many confounding factors that resulted in the better outcomes of women than men in these studies.

Therefore, the purpose of our research is to see whether the female superiority over males remains after controlling for confounding factors. There are several explanations for the sex differences in CRC, including environmental influence, tumour biology, and therapeutic response. First, 


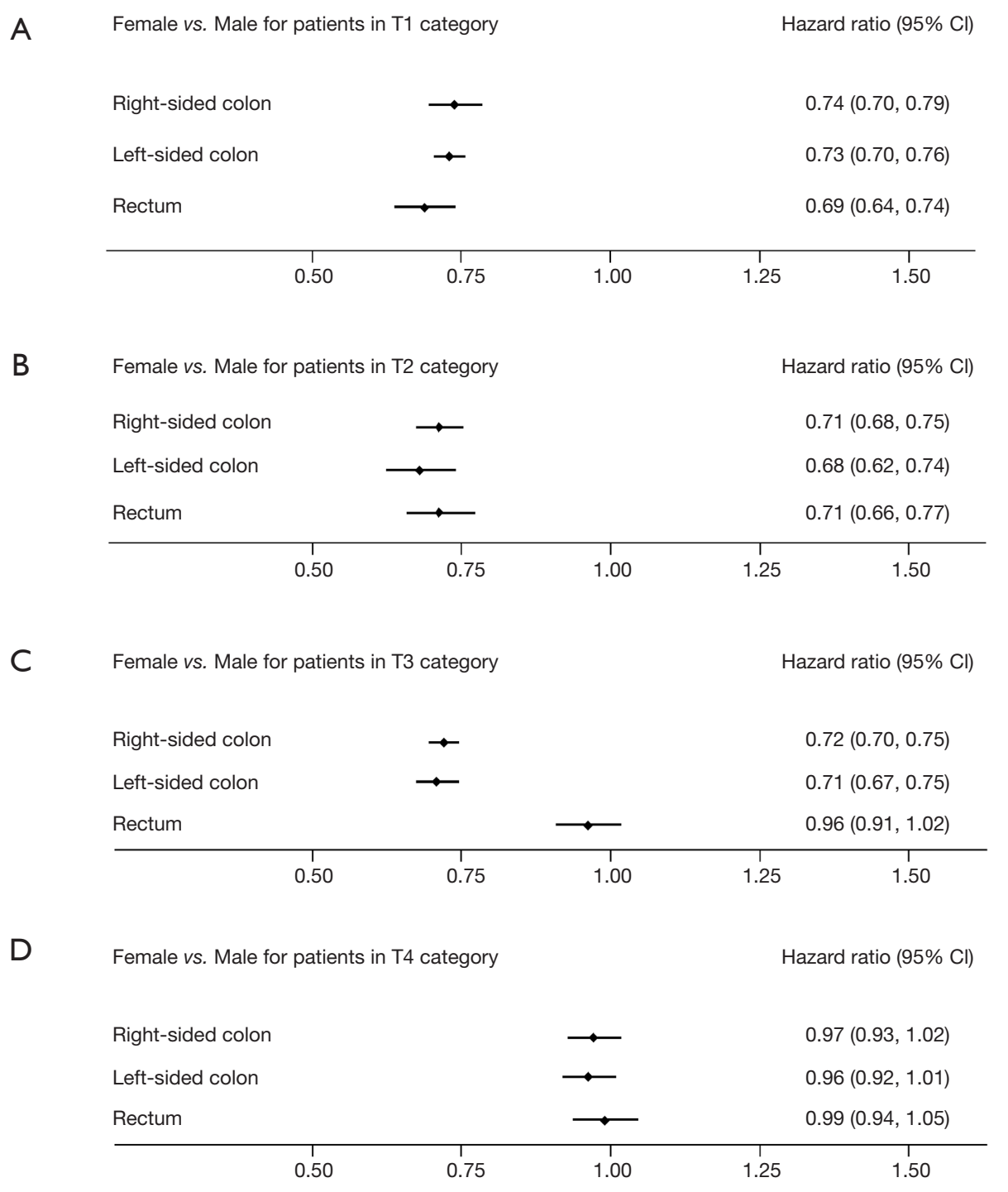

The reference category is males.

Figure 3 Cox proportional hazards model analysis between female and male in T1-3N0M0 CRC patients stratified by T category and primary site. (A) Patients in T1 category; (B) patients in T2 category; (C) patients in T3 category; (D) patients in T4 category.

hormones may be one reason. Postmenopausal hormone use has been linked to a $40 \%$ reduction in CRC in the Women's Health Initiative trial (13). This link between hormone replacement therapy and colon cancer prevention is in line with former reports $(14,15)$. Therefore, we believe that oestrogen may be a confounding factor, so our study cohort included only menopausal women. Menopause is usually defined as 12 months of amenorrhea in females over 45 years of age. It usually starts between 45 and 55 years of age, with an average age of 50.5 years (33). However, there are women who go into menopause after age 55 (34).
Based on the above, we only selected patients aged 60 years and older to form our study cohort to ensure that all female patients were postmenopausal. Next, the biological features of tumors may be different between males and females. There is evidence that females are more likely to develop microsatellite-unstable phenotypes of right-sided tumors $(7,35)$. Furthermore, some reports suggest that females present at a more advanced stage of cancer (18). Consequently, we selected localized CRC of stage T14N0M0 for analysis after stratification of the primary tumour site. Some studies have shown that sex, age, and 


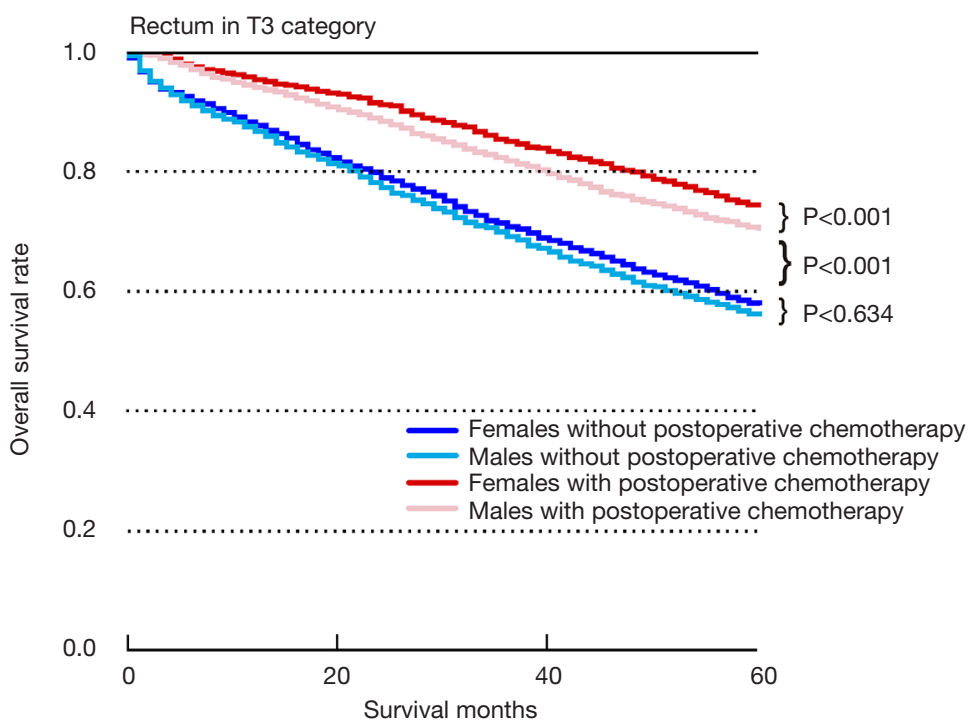

Figure 4 Kaplan-Meier comparison of overall survival among T3N0M0 rectal cancer patients stratified by postoperative chemotherapy.

ethnicity play an important role in the OS of CRC patients. A review of the literature showed that we analyzed the largest cohort of CRC patients, and sex and age had an important impact on the OS of CRC patients. Therefore, we also conducted a detailed analysis stratified by both race and age.

In our analysis, we still found that females had better survival than males withT1-3N0M0 colon cancer and T1-2N0M0 rectal cancer after taking away the effects all available confounding factors. However, there was no difference in survival between sexes among T3N0M0 rectum cancer patients. For rectum tumours with a postoperative pathological stage of T3N0M0, the preoperative clinical stage is often more advanced and may generally be a locally advanced stage, because these patients are often treated with preoperative neoadjuvant treatment. Adjuvant chemotherapy or observation is recommended for pT3N0M0 rectal cancer patients in NCCN guidelines (36). Adjuvant chemotherapy is often recommended for T3rectal cancer patients who with prognostic risk factors. Our results indicated that the T3N0M0 rectum cancer patients who underwent postoperative chemotherapy had a survival benefit over individuals without postoperative chemotherapy, regardless of sex. Meanwhile, there was no significant difference in survival between males and females without postoperative chemotherapy. However, we found that females had a better survival benefit than males in the T3N0M0 rectumcategory with postoperative chemotherapy. These findings might indicate that female may benefit more from postoperative chemotherapy than males in theT3N0M0 rectumcategory. Therefore, in addition to the existence of risk factors, sex can also be considered an indicator for postoperative chemotherapy in T3N0M0 rectum cancer.

Although this research is based on a large number of samples, our research should be interpreted on the background of some limitations, some of which are intrinsic in the design of retrospective studies. Our results may not be representative of young patients with CRC. To exclude the effects of oestrogen on the results, we included only CRC patients aged 60 years and older. Information on radiotherapy and chemotherapy was 'None/Unknown', so we cannot rule out that some of these people had undergone radiotherapy or chemotherapy. Many significant clinical factors, predictive and prognostic biomarkers (e.g., microsatellite instability status), and behavioural differences (e.g., smoking, alcohol, diet, exercise and physical activity) were not available. In addition, there was no information in the SEER database about menopausal status or use of hormone therapy. Thus, there may have been some postmenopausal patients who were still taking oestrogen. Despite these limitations, our large-scale population-based research may make our conclusions more persuasive.

In conclusion, we found that sex was shown to be an independent prognostic factor in T1-3N0M0 colon cancer and T1-2N0M0 rectal cancer. Although a significant OS benefit was not observed in T3N0M0 rectal cancer in the 
overall analysis, females who underwent postoperative chemotherapy had better OS than males among T3N0M0 rectal cancer patients significantly. Hence, our findings indicated that sex might be a predictive and prognostic factor in localized-stage CRC patients.

\section{Acknowledgments}

Funding: This work was supported by the Doctoral Scientific Research Startup Foundation of Liaoning Province (Grant/Award Number: 2019-BS-146), National Science Foundation of China (Grant/Award Number: 81902383), Revitalizing Liaoning Talents Program (Grant/Award Number: XLYC1907004) and Young and Middle-aged Scientific \& Technological Innovation Talent Support Plan of Shenyang City (Grant/Award Number: RC200223).

\section{Footnote}

Reporting Checklist: The authors have completed the STROBE reporting checklist. Available at http://dx.doi. org/10.21037/tcr-20-3421

Peer Review File: Available at http://dx.doi.org/10.21037/tcr20-3421

Conflicts of Interest: All authors have completed the ICMJE uniform disclosure form (available at http://dx.doi. org/10.21037/tcr-20-3421). The authors have no conflicts of interest to declare.

Ethical Statement: The authors are accountable for all aspects of the work in ensuring that questions related to the accuracy or integrity of any part of the work are appropriately investigated and resolved. The study was conducted in accordance with the Declaration of Helsinki (as revised in 2013).

Open Access Statement: This is an Open Access article distributed in accordance with the Creative Commons Attribution-NonCommercial-NoDerivs 4.0 International License (CC BY-NC-ND 4.0), which permits the noncommercial replication and distribution of the article with the strict proviso that no changes or edits are made and the original work is properly cited (including links to both the formal publication through the relevant DOI and the license). See: https://creativecommons.org/licenses/by-nc-nd/4.0/.

\section{References}

1. Siegel RL, Miller KD, Jemal A. Cancer statistics, 2020. CA Cancer J Clin 2020;70:7-30.

2. Paulson EC, Wirtalla C, Armstrong K, et al. Gender influences treatment and survival in colorectal cancer surgery. Dis Colon Rectum 2009;52:1982-91.

3. Koo JH, Jalaludin B, Wong SK, et al. Improved survival in young women with colorectal cancer. Am J Gastroenterol 2008;103:1488-95.

4. van Leeuwen BL, Pahlman L, Gunnarsson U, et al. The effect of age and gender on outcome after treatment for colon carcinoma. A population-based study in the Uppsala and Stockholm region. Crit Rev Oncol Hematol 2008;67:229-36.

5. McArdle CS, McMillan DC, Hole DJ. Male gender adversely affects survival following surgery for colorectal cancer. Br J Surg 2003;90:711-5.

6. Wichmann MW, Muller C, Hornung HM, et al. Gender differences in long-term survival of patients with colorectal cancer. Br J Surg 2001;88:1092-8.

7. Cheung WY, Shi Q, O'Connell M, et al. The predictive and prognostic value of sex in early-stage colon cancer: a pooled analysis of 33,345 patients from the ACCENT database. Clin Colorectal Cancer 2013;12:179-87.

8. Quirt JS, Nanji S, Wei X, et al. Is there a sex effect in colon cancer? Disease characteristics, management, and outcomes in routine clinical practice. Curr Oncol 2017;24:e15-e23.

9. Farquhar CM, Marjoribanks J, Lethaby A, et al. Long term hormone therapy for perimenopausal and postmenopausal women. Cochrane Database Syst Rev 2005;(3):CD004143.

10. Nelson RL, Dollear T, Freels S, et al. The relation of age, race, and gender to the subsite location of colorectal carcinoma. Cancer 1997;80:193-7.

11. Brenner H, Hoffmeister M, Arndt V, et al. Gender differences in colorectal cancer: implications for age at initiation of screening. Br J Cancer 2007;96:828-31.

12. Hendifar A, Yang D, Lenz F, et al. Gender Disparities in Metastatic Colorectal Cancer Survival. Clin Cancer Res 2009;15:6391-7.

13. Chlebowski RT, Wactawski-Wende J, Ritenbaugh C, et al. Estrogen plus progestin and colorectal cancer in postmenopausal women. N Engl J Med 2004;350:991-1004.

14. Newcomb PA, Storer BE. Postmenopausal hormone use and risk of large-bowel cancer. J Natl Cancer Inst 1995;87:1067-71.

15. Mandelson MT, Miglioretti D, Newcomb PA, et al. Hormone replacement therapy in relation to survival 
in women diagnosed with colon cancer. Cancer Causes

Control 2003;14:979-84.

16. Ashktorab H, Smoot DT, Carethers JM, et al. High incidence of microsatellite instability in colorectal cancer from African Americans. Clin Cancer Res 2003;9:1112-7.

17. Elsaleh H, Joseph D, Grieu F, et al. Association of tumour site and sex with survival benefit from adjuvant chemotherapy in colorectal cancer. Lancet 2000;355:1745-50.

18. Woods SE, Basho S, Engel A. The influence of gender on colorectal cancer stage: the state of Ohio, 1996-2001. J Womens Health (Larchmt) 2006;15:877-81.

19. Kauppila JH, Wahlin K, Lagergren P, et al. Sex differences in the prognosis after surgery for esophageal squamous cell carcinoma and adenocarcinoma. Int J Cancer 2019;144:1284-91.

20. Lai MW, Chu YD, Lin CL, et al. Is there a sex difference in postoperative prognosis of hepatocellular carcinoma? BMC Cancer 2019;19:250.

21. Lim JH, Ryu JS, Kim JH, et al. Gender as an independent prognostic factor in small-cell lung cancer: Inha Lung Cancer Cohort study using propensity score matching. PLoS One 2018;13:e0208492.

22. Matteoni S, Abbruzzese C, Villani V, et al. The influence of patient sex on clinical approaches to malignant glioma. Cancer Lett 2020;468:41-7.

23. Stokes WA, Camilon PR, Banglawala SM, et al. Is sex an independent prognostic factor in esthesioneuroblastoma? Am J Rhinol Allergy 2015;29:369-72.

24. Tian M, Ma W, Chen Y, et al. Impact of gender on the survival of patients with glioblastoma. Biosci Rep 2018;38:BSR20180752.

25. O'Leary KE, Cruess DG, Pleau D, et al. Sex differences in associations between psychosocial factors and aberrant crypt foci among patients at risk for colon cancer. Gend

Cite this article as: Ma B, Li Y, Meng Q. The predictive and prognostic value of sex in localized colorectal cancer: a SEER-based analysis. Transl Cancer Res 2021;10(5):2108-2119. doi: $10.21037 /$ tcr-20-3421
Med 2011;8:165-71.

26. Carr PR, Amitay EL, Jansen L, et al. Association of $\mathrm{BMI}$ and major molecular pathological markers of colorectal cancer in men and women. Am J Clin Nutr 2020;111:562-9.

27. Molife R, Lorigan P, MacNeil S. Gender and survival in malignant tumours. Cancer Treat Rev 2001;27:201-9.

28. Ferguson MK, Skosey C, Hoffman PC, et al. Sexassociated differences in presentation and survival in patients with lung cancer. J Clin Oncol 1990;8:1402-7.

29. Edgren G, Liang L, Adami HO, et al. Enigmatic sex disparities in cancer incidence. Eur J Epidemiol 2012;27:187-96.

30. Dorak MT, Karpuzoglu E. Gender differences in cancer susceptibility: an inadequately addressed issue. Front Genet 2012;3:268.

31. Chapuis PH, Dent OF, Fisher R, et al. A multivariate analysis of clinical and pathological variables in prognosis after resection of large bowel cancer. Br J Surg 1985;72:698-702.

32. Newland RC, Dent OF, Lyttle MN, et al. Pathologic determinants of survival associated with colorectal cancer with lymph node metastases. A multivariate analysis of 579 patients. Cancer 1994;73:2076-82.

33. Nichols HB, Trentham-Dietz A, Hampton JM, et al. From menarche to menopause: trends among US Women born from 1912 to 1969. Am J Epidemiol 2006;164:1003-11.

34. McKinlay SM, Brambilla DJ, Posner JG. The normal menopause transition. Maturitas 1992;14:103-15.

35. Meguid RA, Slidell MB, Wolfgang CL, et al. Is there a difference in survival between right- versus left-sided colon cancers? Ann Surg Oncol 2008;15:2388-94.

36. Rectal Cancer, Version 2.2019, NCCN Clinical Practice Guidelines in Oncology. Available online: www.nccn.org/ patients 
Supplementary

Table S1 Prognostic factors in COX proportional hazard model in CRC of T1 category

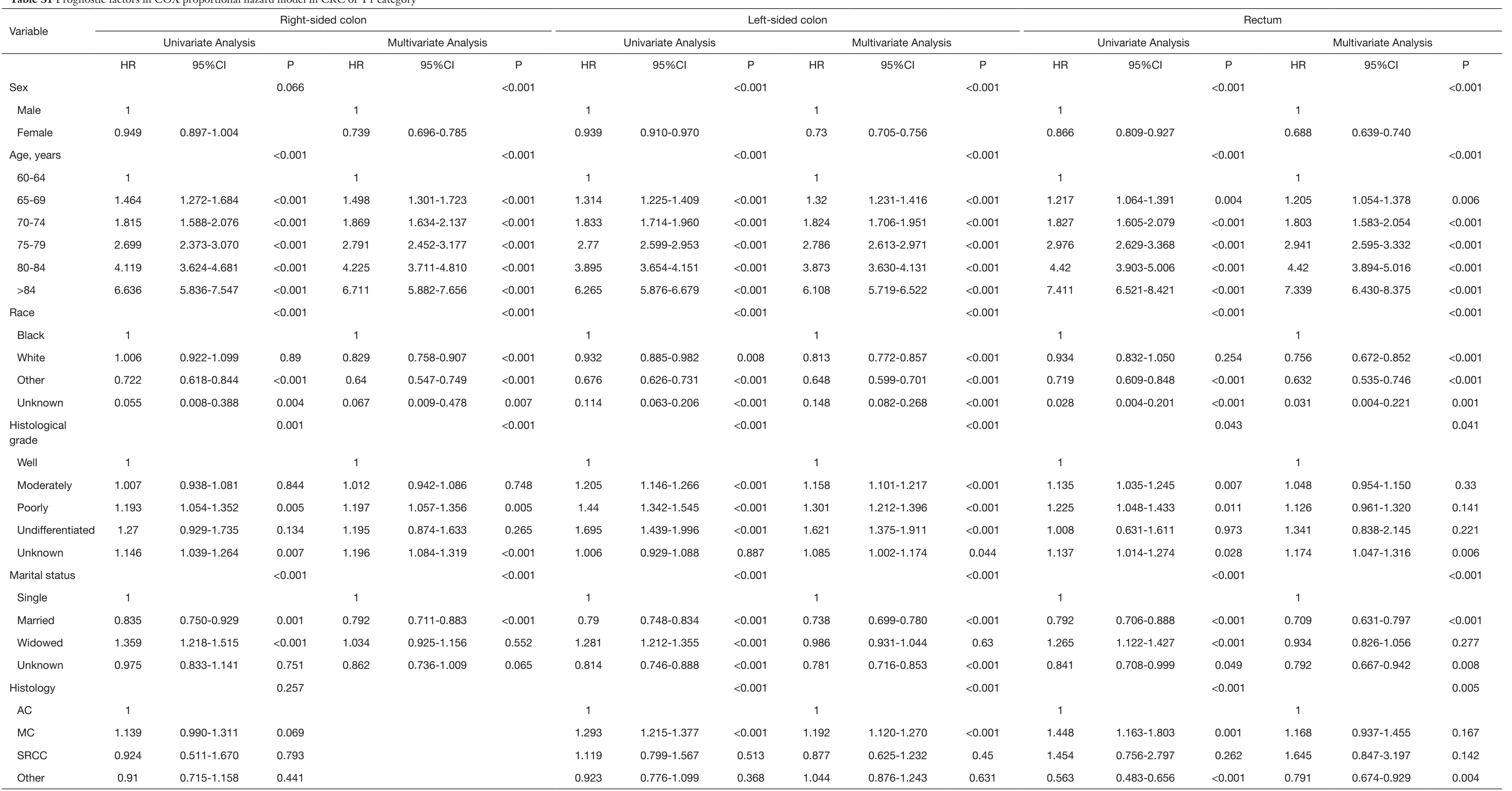




\begin{tabular}{|c|c|c|c|c|c|c|c|c|c|c|c|c|c|c|c|c|c|c|}
\hline \multirow{3}{*}{ Variable } & \multicolumn{6}{|c|}{ Right-sided colon } & \multicolumn{6}{|c|}{ Left-sided colon } & \multicolumn{6}{|c|}{ Rectum } \\
\hline & \multicolumn{3}{|c|}{ Univariate Analysis } & \multicolumn{3}{|c|}{ Multivariate Analysis } & \multicolumn{3}{|c|}{ Univariate Analysis } & \multicolumn{3}{|c|}{ Multivariate Analysis } & \multicolumn{3}{|c|}{ Univariate Analysis } & \multicolumn{3}{|c|}{ Multivariate Analysis } \\
\hline & $\mathrm{HR}$ & $95 \% \mathrm{Cl}$ & $\mathrm{P}$ & HR & $95 \% \mathrm{Cl}$ & $\mathrm{P}$ & HR & $95 \% \mathrm{Cl}$ & $\mathrm{P}$ & HR & $95 \% \mathrm{Cl}$ & $\mathrm{P}$ & HR & $95 \% \mathrm{Cl}$ & $\mathrm{P}$ & HR & $95 \% \mathrm{Cl}$ & $\mathrm{P}$ \\
\hline Sex & & & $<0.001$ & & & $<0.001$ & & & $<0.001$ & & & $<0.001$ & & & 0.005 & & & $<0.001$ \\
\hline Female & 0.914 & $0.870-0.962$ & & 0.713 & $0.675-0.753$ & & 0.855 & $0.789-0.926$ & & 0.680 & $0.624-0.740$ & & 0.900 & $0.836-0.969$ & & 0.713 & $0.658-0.773$ & \\
\hline Age, years & & & $<0.001$ & & & $<0.001$ & & & $<0.001$ & & & $<0.001$ & & & $<0.001$ & & & $<0.001$ \\
\hline $60-64$ & 1 & & & 1 & & & 1 & & & 1 & & & 1 & & & 1 & & \\
\hline $65-69$ & 1.373 & $1.186-1.590$ & $<0.001$ & 1.398 & $1.207-1.619$ & $<0.001$ & 1.354 & $1.133-1.617$ & 0.001 & 1.371 & $1.147-1.638$ & 0.001 & 1.626 & $1.375-1.923$ & 0.000 & 1.655 & $1.399-1.957$ & 0.000 \\
\hline $70-74$ & 1.956 & $1.707-2.241$ & $<0.001$ & 2.004 & $1.749-2.297$ & $<0.001$ & 1.725 & $1.453-2.048$ & $<0.001$ & 1.734 & $1.460-2.059$ & $<0.001$ & 2.431 & $2.073-2.851$ & 0.000 & 2.479 & $2.114-2.908$ & 0.000 \\
\hline 75-79 & 2.513 & $2.206-2.863$ & $<0.001$ & 2.585 & $2.267-2.946$ & $<0.001$ & 2.745 & $2.334-3.228$ & $<0.001$ & 2.801 & $2.380-3.297$ & $<0.001$ & 3.380 & $2.897-3.944$ & 0.000 & 3.463 & $2.965-4.044$ & 0.000 \\
\hline $80-84$ & 4.184 & $3.683-4.753$ & $<0.001$ & 4.294 & $3.775-4.884$ & $<0.001$ & 4.079 & $3.469-4.797$ & $<0.001$ & 4.161 & $3.533-4.902$ & $<0.001$ & 4.837 & $4.147-5.643$ & 0.000 & 4.997 & $4.277-5.839$ & 0.000 \\
\hline$>84$ & 6.336 & $5.581-7.193$ & $<0.001$ & 6.475 & $5.689-7.369$ & $<0.001$ & 6.179 & $5.245-7.279$ & $<0.001$ & 6.213 & $5.255-7.345$ & $<0.001$ & 7.926 & $6.776-9.271$ & 0.000 & 8.359 & $7.119-9.814$ & 0.000 \\
\hline Race & & & $<0.001$ & & & $<0.001$ & & & 0.076 & & & 0.017 & & & $<0.001$ & & & $<0.001$ \\
\hline Black & 1 & & & 1 & & & 1 & & & 1 & & & 1 & & & 1 & & \\
\hline White & 1.010 & $0.926-1.102$ & 0.818 & 0.837 & $0.767-0.913$ & $<0.001$ & 0.978 & $0.853-1.122$ & 0.752 & 0.813 & $0.707-0.934$ & 0.003 & 0.860 & $0.749-0.987$ & 0.032 & 0.745 & $0.648-0.857$ & 0.000 \\
\hline Other & 0.606 & $0.513-0.716$ & $<0.001$ & 0.565 & $0.478-0.668$ & $<0.001$ & 0.841 & $0.694-1.018$ & 0.076 & 0.794 & $0.655-0.963$ & 0.019 & 0.654 & $0.538-0.795$ & 0.000 & 0.588 & $0.483-0.715$ & 0.000 \\
\hline Unknown & 0.219 & $0.070-0.680$ & 0.009 & 0.249 & $0.080-0.776$ & 0.016 & 0.314 & $0.078-1.262$ & 0.103 & 0.371 & $0.092-1.493$ & 0.163 & 0.150 & $0.021-1.072$ & 0.059 & 0.168 & $0.024-1.200$ & 0.075 \\
\hline Well & 1 & & & & & & 1 & & & & & & 1 & & & & & \\
\hline Moderately & 1.032 & $0.953-1.118$ & 0.436 & & & & 1.038 & $0.921-1.169$ & 0.540 & & & & 1.015 & $0.893-1.152$ & 0.824 & & & \\
\hline Poorly & 1.122 & $1.009-1.248$ & 0.033 & & & & 1.003 & $0.827-1.216$ & 0.974 & & & & 1.161 & $0.981-1.375$ & 0.083 & & & \\
\hline Undifferentiated & 0.983 & $0.773-1.249$ & 0.887 & & & & 1.238 & $0.749-2.046$ & 0.405 & & & & 1.019 & $0.632-1.642$ & 0.939 & & & \\
\hline Unknown & 1.110 & $0.926-1.331$ & 0.260 & & & & 1.149 & $0.867-1.524$ & 0.334 & & & & 1.012 & $0.820-1.250$ & 0.911 & & & \\
\hline Marital status & & & $<0.001$ & & & $<0.001$ & & & $<0.001$ & & & $<0.001$ & & & $<0.001$ & & & $<0.001$ \\
\hline Single & 1 & & & 1 & & & 1 & & & 1 & & & 1 & & & 1 & & \\
\hline Married & 0.818 & $0.745-0.898$ & $<0.001$ & 0.750 & $0.682-0.825$ & $<0.001$ & 0.815 & $0.706-0.940$ & 0.005 & 0.742 & $0.642-0.857$ & $<0.001$ & 0.874 & $0.766-0.997$ & 0.045 & 0.813 & $0.711-0.929$ & 0.002 \\
\hline Widowed & 1.258 & $1.145-1.382$ & $<0.001$ & 0.951 & $0.864-1.047$ & 0.309 & 1.266 & 1.093-1.467 & 0.002 & 0.986 & $0.848-1.146$ & 0.850 & 1.267 & 1.106-1.451 & 0.001 & 0.946 & $0.823-1.088$ & 0.437 \\
\hline Unknown & 0.898 & $0.772-1.045$ & 0.165 & 0.763 & $0.655-0.888$ & $<0.001$ & 1.074 & $0.852-1.354$ & 0.545 & 0.963 & $0.764-1.215$ & 0.753 & 1.026 & $0.820-1.283$ & 0.824 & 0.859 & $0.687-1.075$ & 0.185 \\
\hline Histology & & & 0.021 & & & 0.026 & & & 0.246 & & & & & & 0.034 & & & \\
\hline $\mathrm{AC}$ & 1 & & & 1 & & & 1 & & & & & & 1 & & & & & \\
\hline MC & 1.114 & $1.030-1.205$ & 0.007 & 1.078 & $0.997-1.166$ & 0.059 & 1.144 & $0.970-1.351$ & 0.111 & & & & 1.105 & $0.915-1.334$ & 0.298 & & & \\
\hline SRCC & 0.968 & $0.601-1.558$ & 0.894 & 0.936 & $0.581-1.507$ & 0.786 & 1.430 & $0.642-3.188$ & 0.381 & & & & 2.847 & $1.355-5.982$ & 0.006 & & & \\
\hline Other & 1.204 & $0.964-1.503$ & 0.102 & 1.320 & $1.057-1.648$ & 0.014 & 1.258 & $0.791-2.001$ & 0.331 & & & & 1.004 & $0.750-1.344$ & 0.977 & & & \\
\hline
\end{tabular}

$\mathrm{AC}$, adenocarcinoma; $\mathrm{MC}$, Mucinous adenocarcinoma; $\mathrm{SRCC}$, Signet ring cell carcinoma; $\mathrm{HR}$, Hazard ratio; $\mathrm{Cl}$, Confidence interval. 
Table S3 Prognostic factors in COX proportional hazard model in CRC of T3 category

\begin{tabular}{|c|c|c|c|c|c|c|c|c|c|c|c|c|}
\hline \multirow{3}{*}{ Variable } & \multicolumn{6}{|c|}{ Right-sided colon } & \multicolumn{6}{|c|}{ Left-sided colon } \\
\hline & \multicolumn{3}{|c|}{ Univariate Analysis } & \multicolumn{3}{|c|}{ Multivariate Analysis } & \multicolumn{3}{|c|}{ Univariate Analysis } & \multicolumn{3}{|c|}{ Multivariate Analysis } \\
\hline & $H R$ & $95 \% \mathrm{Cl}$ & $\mathrm{P}$ & $H R$ & $95 \% \mathrm{Cl}$ & $\mathrm{P}$ & $\mathrm{HR}$ & $95 \% \mathrm{Cl}$ & $\mathrm{P}$ & $H R$ & $95 \% \mathrm{Cl}$ & $\mathrm{P}$ \\
\hline Sex & & & $<0.001$ & & & $<0.001$ & & & $<0.001$ & & & $<0.001$ \\
\hline Male & 1 & & & 1 & & & 1 & & & 1 & & \\
\hline Female & 0.904 & $0.876-0.933$ & & 0.721 & $0.696-0.746$ & & 0.885 & $0.845-0.927$ & & 0.708 & $0.674-0.745$ & \\
\hline Age, years & & & $<0.001$ & & & $<0.001$ & & & $<0.001$ & & & $<0.001$ \\
\hline $60-64$ & 1 & & & 1 & & & 1 & & & 1 & & \\
\hline $65-69$ & 1.36 & $1.243-1.489$ & $<0.001$ & 1.375 & $1.256-1.505$ & $<0.001$ & 1.342 & $1.206-1.493$ & $<0.001$ & 1.345 & $1.208-1.497$ & $<0.001$ \\
\hline $70-74$ & 1.798 & $1.652-1.956$ & $<0.001$ & 1.84 & $1.690-2.002$ & $<0.001$ & 1.808 & $1.633-2.002$ & $<0.001$ & 1.801 & $1.626-1.994$ & $<0.001$ \\
\hline $75-79$ & 2.663 & $2.458-2.885$ & $<0.001$ & 2.72 & $2.510-2.948$ & $<0.001$ & 2.640 & $2.396-2.908$ & $<0.001$ & 2.666 & $2.419-2.938$ & $<0.001$ \\
\hline $80-84$ & 3.658 & $3.383-3.956$ & $<0.001$ & 3.748 & $3.464-4.057$ & $<0.001$ & 3.470 & $3.150-3.822$ & $<0.001$ & 3.484 & $3.160-3.841$ & $<0.001$ \\
\hline$>84$ & 5.462 & $5.056-5.900$ & $<0.001$ & 5.581 & $5.158-6.038$ & $<0.001$ & 5.609 & $5.097-6.171$ & $<0.001$ & 5.574 & $5.056-6.144$ & $<0.001$ \\
\hline Race & & & $<0.001$ & & & $<0.001$ & & & $<0.001$ & & & $<0.001$ \\
\hline Black & 1 & & & 1 & & & 1 & & & 1 & & \\
\hline White & 1.079 & $1.021-1.140$ & 0.007 & 0.892 & $0.843-0.943$ & $<0.001$ & 0.960 & 0.890-1.035 & 0.284 & 0.835 & $0.774-0.901$ & $<0.001$ \\
\hline Other & 0.796 & $0.726-0.872$ & $<0.001$ & 0.719 & $0.656-0.788$ & $<0.001$ & 0.659 & $0.587-0.739$ & $<0.001$ & 0.622 & $0.555-0.698$ & $<0.001$ \\
\hline Unknown & 0.278 & $0.139-0.558$ & $<0.001$ & 0.275 & $0.137-0.552$ & $<0.001$ & 0.291 & $0.130-0.651$ & 0.003 & 0.348 & $0.156-0.778$ & $<0.001$ \\
\hline Histological grade & & & $<0.001$ & & & & & & 0.001 & & & $<0.001$ \\
\hline Well & 1 & & & & & & 1 & & & 1 & & \\
\hline Moderately & 1.034 & $0.972-1.100$ & 0.285 & & & & 1.051 & $0.963-1.147$ & 0.261 & 1.079 & $0.989-1.178$ & 0.087 \\
\hline Poorly & 1.133 & $1.058-1.213$ & $<0.001$ & & & & 1.207 & $1.082-1.346$ & 0.001 & 1.185 & $1.062-1.321$ & 0.002 \\
\hline Undifferentiated & 1.122 & $0.996-1.263$ & 0.059 & & & & 1.407 & $1.122-1.764$ & 0.003 & 1.498 & $1.195-1.879$ & $<0.001$ \\
\hline Unknown & 1.163 & $1.024-1.320$ & 0.02 & & & & 1.390 & $1.159-1.667$ & $<0.001$ & 1.416 & $1.181-1.699$ & $<0.001$ \\
\hline Marital status & & & $<0.001$ & & & $<0.001$ & & & $<0.001$ & & & $<0.001$ \\
\hline Single & 1 & & & 1 & & & 1 & & & 1 & & \\
\hline Married & 0.788 & $0.744-0.834$ & $<0.001$ & 0.724 & $0.683-0.767$ & $<0.001$ & 0.833 & 0.769-0.902 & $<0.001$ & 0.774 & $0.714-0.839$ & $<0.001$ \\
\hline Widowed & 1.173 & $1.108-1.242$ & $<0.001$ & 0.909 & $0.857-0.963$ & 0.001 & 1.272 & 1.173-1.379 & $<0.001$ & 1.029 & $0.947-1.118$ & 0.499 \\
\hline Unknown & 0.959 & $0.875-1.051$ & 0.373 & 0.822 & $0.750-0.901$ & $<0.001$ & 1.007 & $0.879-1.154$ & 0.923 & 0.898 & $0.783-1.029$ & 0.121 \\
\hline Histology & & & 0.005 & & & 0.038 & & & 0.023 & & & \\
\hline$A C$ & 1 & & & 1 & & & 1 & & & & & \\
\hline MC & 1.07 & $1.024-1.119$ & 0.003 & 1.059 & $1.013-1.107$ & 0.012 & 1.132 & $1.042-1.231$ & 0.004 & & & \\
\hline SRCC & 1.111 & $0.943-1.309$ & 0.207 & 1.095 & $0.929-1.289$ & 0.28 & 0.973 & $0.586-1.615$ & 0.915 & & & \\
\hline Other & 1.121 & $0.989-1.271$ & 0.074 & 1.08 & $0.953-1.225$ & 0.227 & 1.180 & $0.874-1.592$ & 0.280 & & & \\
\hline
\end{tabular}

AC, adenocarcinoma; MC, Mucinous adenocarcinoma; SRCC, Signet ring cell carcinoma; HR, Hazard ratio; Cl, Confidence interval. 
Table S4 Univariate Analysis stratified by T category and Age/Race/Histology

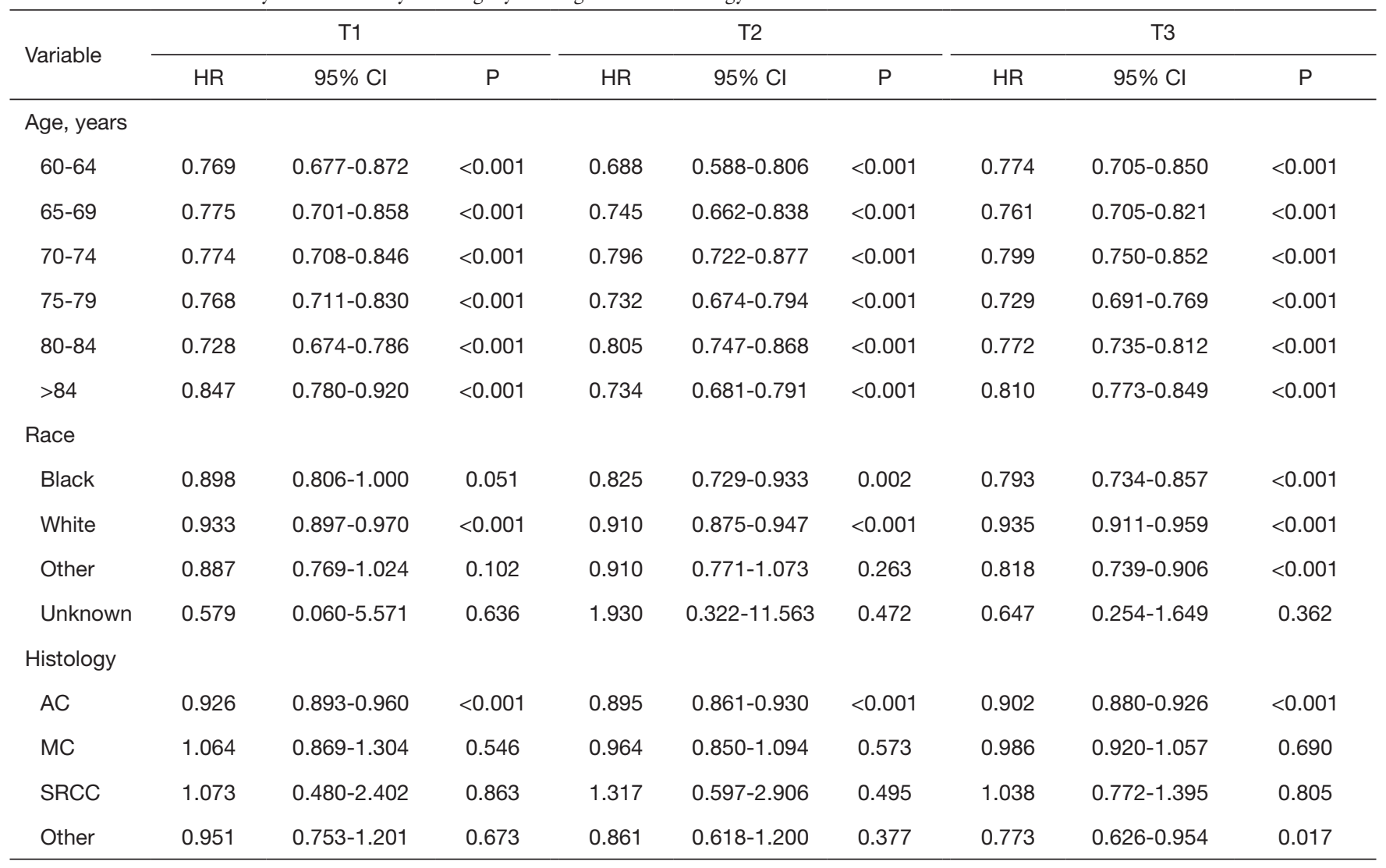

AC, adenocarcinoma; MC, Mucinous adenocarcinoma; SRCC, Signet ring cell carcinoma; HR, Hazard ratio; Cl, Confidence interval. 